\title{
CICLO DE VIDA DOS SISTEMAS: UMA ANÁLISE DOS DESAFIOS DA IMPLEMENTAÇÃO DE UM SISTEMA DE INFORMAÇẢO EM UMA INSTITUIÇÃO DE SAỦDE PÚBLICA
}

\author{
SYSTEMS LIFE CYCLE: AN ANALYSIS OF THE CHALLENGES OF \\ IMPLEMENTING AN INFORMATION SYSTEM IN A PUBLIC HEALTH \\ INSTITUTION
}

\author{
Data de submissão: $15 / 01 / 2015$ \\ Aceite: 02/03/2016 \\ Eliete dos Reis Lehnhart ${ }^{1}$ \\ Tiago Chiapinotto da Silva ${ }^{2}$ \\ Vanderléia Leal Losekann ${ }^{3}$ \\ Mauri Leodir Löbler ${ }^{4}$ \\ Rafaela Dutra Tagliapietra ${ }^{5}$
}

\section{RESUMO}

O objetivo deste estudo foi investigar o processo de implementação de um sistema de informação em uma instituição pública de saúde, localizada num município do interior do Rio Grande do Sul. Para tanto, utilizou-se a estratégia de estudo de caso, através de entrevistas semiestruturadas, realizadas com a equipe responsável pelo projeto de implementação do sistema, a partir do conceito de ciclo de vida dos sistemas de informação proposto por Audy, Andrade e Cidral (2005). Os resultados demonstram que a instituição encontra-se na fase de instalação do sistema adquirido. Também foi possível identificar alguns problemas enfrentados no transcorrer do projeto, bem como ganhos diretos e indiretos para a administração pública e para os pacientes da rede pública de saúde do município.

Palavras-chave: Sistemas de Informação. Instituição Pública de Saúde. Fase de Implantação de Software.

\footnotetext{
1 Possui graduação, mestrado e doutorado em Administração pela Universidade Federal de Santa Maria, UFSM. Atualmente é professora do Departamento de Ciências Administrativas da UFSM Santa Maria. Rio Grande do Sul. Brasil. E-mail: elietedosreis@gmail.com

2 Possui graduação em Administração de Empresas pela Universidade Norte do Paraná, UNOPAR, especialista em Gestão de Finanças e da Informação pela Faculdade Palotina de Santa Maria. Santa Maria. Rio Grande do Sul. Brasil. E-mail:tiagochiapinotto@yahoo.com.br 3 Possui graduação em Matemática pela Universidade Federal de Santa Maria, UFSM, graduação em Administração pela Universidade de Santo Amaro, UNISA, mestrado em Administração pela Universidade Federal de Santa Maria, UFSM. Atualmente é professora da Faculdade Palotina e Técnica em Educação na Universidade Federal de Santa Maria. Santa Maria. Rio Grande do Sul. E-mail: vanderleialeallosekann@ ymail.com

4 Possui graduação em Administração pela Universidade Federal de Santa Maria, UFSM, mestrado em Engenharia de Produção pela Universidade Federal de Santa Maria, UFSM e doutorado em Administração pela Universidade Federal do Rio Grande do Sul, UFRGS. Atualmente é diretor do Centro de Ciências Sociais e Humanas da Universidade Federal de Santa Maria, UFSM. Santa Maria. Rio Grande do Sul.E-mail: lobler@ccsh.ufsm.br

5 Possui graduação em Administração, graduação em andamento pelo Programa Especial de Graduação de Formação de Professores para a Educação e Mestrado em andamento em Administração pela Universidade Federal de Santa Maria, UFSM. Santa Maria. Rio Grande do Sul. E-mail: rafatagliapietra@gmail.com
} 


\begin{abstract}
The objective of this study was to investigate the process of implementation of an information system in a public health institution located in a city in the interior of Rio Grande do Sul. For this we used the case study strategy, through semi-structured interviews with the team responsible for system implementation project, from the concept of life cycle of information systems proposed by Audy, Andrade and Cidral (2005). The results demonstrate that the institution is in the system installation phase. It was also possible to identify some problems faced in the course of the project, as well as direct and indirect gains for public administration and for patients from public municipal health.
\end{abstract}

Keywords: Information Systems. Public Health Institution. Deployment Phase to Software.

\title{
1 INTRODUÇÃO
}

Atualmente, é notório o avanço acelerado da Tecnologia da Informação (TI), por meio da evolução de hardware, com máquinas cada vez mais potentes, e da evolução de softwares de gestão e controle de processos. Segundo a IDC Brasil, empresa líder em inteligência de mercado, serviços de consultoria e conferências com as indústrias de Tecnologia da Informação e Telecomunicações, embora o crescimento dos investimentos na área de tecnologia da informação e telecomunicações previstos para 2016 seja de 2,6\% em comparação a 2015, novos modelos de negócios continuarão a ganhar espaço em 2016, suportados pelos pilares da 3a Plataforma - cloud, mobilidade, mídias sociais e big data (IDC BRASIL, 2016). Tendo em vista que o avanço dessas tecnologias exige uma evolução do tema de segurança nas empresas, a participação do orçamento de segurança avançará ao menos 2 pontos percentuais no orçamento de TI das empresas e representa um desafio para os gestores, demonstrando grandes investimentos e atenção para esta área.

Na pesquisa publicada pela Escola de Administração de São Paulo da Fundação Getúlio Vargas (2014), as empresas investiram 7,5\% da sua receita em TI. Segundo a mesma pesquisa, o custo anual por usuário gira em torno de $\mathrm{R} \$ 26.000,00$. Da mesma forma, instituições públicas estão modernizando seu portfólio de sistemas, ajustando-se, assim, as exigências de seus clientes internos e externos.

Neste contexto de grandes investimentos e atenção aplicada, o conceito de TI dentro das organizações vai muito além da disponibilização de computadores, engloba uma estrutura robusta que tem diversos componentes, profissionais capacitados, rede lógica, infraestrutura de telecomunicação, instalação elétrica, hardware apropriado e sistemas de informação específicos para os fins da organização.

Assim, a informação é fundamental dentro da organização, pois a partir dela são balizados planejamentos futuros e realizadas análises de desempenho histórico, dentre outros. Então, para que se tenham informações adequadas, confiáveis e no tempo correto é fundamental que as instituições implantem sistemas de informações específicos a sua realidade. Neste contexto, tendo em vista o rápido crescimento dos sistemas de informação e das reflexões associadas a sua importância, organizações, mercados e indústrias criaram uma crença generalizada de que um sistema de informação é fundamental para sobrevivência e desenvolvimento organizacional (ABUGABAH e SANZOGNI, 2009).

Um sistema de informação eficaz disponibiliza aos gestores informações por meio de uma visão ampla do negócio com ferramentas que permitem a tomada de decisões embasadas em informações históricas concretas, aumentando, assim, sua assertividade. E, na maioria das vezes, um sistema de informação eficiente significa a sobrevivência da organização no mercado. Dessa forma, de acordo com Watson (2007), um sistema de informação é implementado nas organizações para melhorar a eficiência dos seus processos. 
A implantação de sistemas de informações nas organizações é um processo que deve ser estudado e planejado cuidadosamente, uma vez que envolvem diversos atores e relacionamento das mais diversas áreas. Normalmente, este fenômeno é entendido como um projeto de caráter temporário composto por fases claramente definidas. As fases de implementação de um sistema, dentro de uma organização, são perfeitamente caracterizadas em cada uma de suas etapas, iniciando pela verificação da necessidade e indo até a manutenção do sistema já em operação dentro da organização (AUDY, ANDRADE e CIDRAL, 2005).

Nas instituições públicas, o desenvolvimento e o aprimoramento de sistemas de informação são de grande relevância para o apoio à gestão, gerando informações confiáveis e de valor estratégico. Em se tratando de sistemas de informações específicos para a gestão da saúde pública, torna-se ainda mais relevante a sua aplicação. No entanto, a ênfase no desenvolvimento desses softwares tem sido em sistemas clínicos, especialmente registro eletrônico de pacientes, em vez de desenvolvimento de sistemas de informação integrados para a gestão (KIVINEN e LAMMINTAKANEN, 2013).

Diante deste cenário, este estudo visa investigar o processo de implementação de um sistema de informação no sistema público de saúde de um município do interior do Rio Grande do Sul. Este estudo foi desenvolvido com base no ciclo de vida dos sistemas de informação. $O$ sistema informado está sendo implantado em todas as unidades de saúde do município em tela, com o objetivo de apoiar, entre outros, a gestão dos prontuários médicos, dos atendimentos realizados, do planejamento da compra de medicamentos, do histórico de consumo e do monitoramento dos indicadores de gestão.

Esta pesquisa está estruturada em mais quatro seções, além da introdução: na seção dois, aborda-se o referencial teórico que balizou a realização deste estudo. Na seção três, é apresentada a arquitetura metodológica que possibilitou a operacionalização da pesquisa. Na seção quatro, são apresentados os resultados alinhados com os objetivos propostos. Na seção cinco, abordam-se as considerações finais e, por fim, as referências bibliográficas utilizadas no estudo em questão.

\section{REFERENCIAL TEÓRICO}

\subsection{Sistemas de Informação}

Sistema de informação é definido por Laudon e Laudon (2007) como um conjunto de componentes inter-relacionados que coletam (ou recuperam), processam, armazenam e distribuem informações destinadas a apoiar a tomada de decisões, a coordenação e o controle de uma organização. Os sistemas de informação não necessariamente são informatizados, porém, segundo Turban, Rainer e Potter (2005), a maioria deles é informatizada. Ainda esses autores os classificam como sendo Sistemas de Informação Baseados em Computador (SIBC), sendo definidos como um sistema que utiliza a tecnologia de computador para realizar algumas ou todas as suas tarefas.

Os sistemas de informação apoiam a gestão na organização e controle dos fluxos de trabalho, além disso, auxiliam os trabalhadores a gerenciar sua própria rotina de trabalho bem como criar soluções alternativas para os problemas rotineiros. Audy, Andrade e Cidral (2005) citam como objetivo geral dos sistemas de informação a função de disponibilizar informações necessárias para que as organizações atuem em um determinado ambiente, sendo este projetado para cumprir três metas básicas, "suporte a estratégias competitivas e obtenção de vantagens competitivas", "suporte ao processo decisório dos diversos níveis organizacionais" e "suporte ao processo de integração dos processos de negócio e funções organizacionais". 
No contexto da eficiência dentro das organizações, os sistemas de informação passam a ser uma ferramenta essencial para a otimização das empresas. Dessa forma, Rezende e Abreu (2008) descrevem que trabalhar com informações de valor será um diferencial para as grandes organizações, a informação e o conhecimento serão as maiores armas dos profissionais que desejam destacar-se no mercado, efetivar a perenidade, a sobrevivência, a competitividade e a inteligência empresarial.

Sant'anna et al.(2011) citam que é cada vez mais claro que o tomador de decisões necessita de informações alicerçadas em relatórios gerados a partir de softwares específicos para este fim, desta forma trabalha com margens de erro quase inexistentes, o que contribui significativamente para a tomada de decisão.

No que se refere aos tipos de sistema na literatura especializada, são encontradas diversas formas de classificação dos sistemas de informação, no entanto, neste estudo, a ênfase recai sobre o sistema de Planejamento de Recursos Empresariais (ERP), tendo em vista ser este o tipo de sistema em implantação no caso em estudo.

De acordo com Alves e Matos (2011), o ERP consiste em pacote de software integrado composto por um conjunto de módulos funcionais padrão que podem ser adaptados às necessidades específicas de cada organização, com a finalidade de dar suporte à maioria das operações. Para Souza e Zwicker (2000), os sistemas ERP podem ser definidos como sistemas de informação integrados, sendo adquiridos na forma de pacotes comerciais de software, a fim de servir como suporte à maioria das operações de uma organização. Nesta mesma linha, O'Leary (2002) argumenta que sistemas ERP concentram-se em processos, em vez de funções individuais, fornecendo capacidades de processamento e de transações que ajudam a integrar todo o processamento de transações de uma empresa. Dessa forma, esses sistemas podem ser um instrumento para transformar as organizações funcionais em organizações por processo (SANJA, 2013).

Conforme Santos (2013), o desenvolvimento de sistemas ERP iniciou com módulos de controle de estoques, contabilidade, gestão financeira, planejamento de recursos e necessidades de materiais MRP I, MRP II (Manufactruing Resoure Planning). Posteriormente expandiu com a inclusão de outros processos como vendas, marketing, compras, custos, recursos humanos e assim por diante. Para o autor, atualmente existem no Brasil e no exterior várias empresas que oferecem produtos ERP incrementados com funções que produzem informação de apoio a todos os níveis organizacionais, como por exemplo, SAP, Financial Oracle, Totvs, PeopleSoft, Benner, Datasul, Microsiga, Logocenter, Procente e muitas outras.

Segundo O'Leary (2002), a arquitetura dos sistemas ERP geralmente é baseada em um sistema de banco de dados relacional como, por exemplo, o Oracle. Dessa forma, usando um banco de dados relacional e um processo apropriado, o sistema permite a captura de dados e, em seguida, pode gerar relatórios de modo que todos os usuários tenham acesso à mesma informação, permitindo maior congruência nas informações. Assim, o ERP pode ser utilizado não só em empresas de manufatura, mas em qualquer organização que queira aumentar a sua competitividade, mais efetivamente, usando todos os seus bens, incluindo a informação (SHANKARNARAYANAN, 2014).

No entendimento de Souza e Zwicker (2000), os sistemas ERP possuem uma série de características que, tomadas em conjunto, os distinguem de sistemas desenvolvidos internamente nas empresas e de outros pacotes comerciais. As principais características de um sistema ERP considerados na literatura são: pacotes de softwares comerciais; modelo padrão dos processos de negócios; integração das diversas áreas da empresa; utilização de um banco de dados corporativos; grande abrangência funcional e requerem procedimentos de ajuste. 


\subsection{Ciclo de vida dos sistemas de informação}

O presente trabalho visa investigar a implementação de um sistema de informação, a partir do conceito de ciclo de vida dos sistemas de informação proposto por Audy, Andrade e Cidral (2005). Dessa forma, são apresentados os principais conceitos relativos a este tema específico, bem como as fases específicas do modelo proposto por esses autores.

Segundo Audy, Andrade e Cidral (2005), o ciclo de vida dos sistemas é considerado um processo evolucionário constituído de fases pelas quais um sistema passa desde seu planejamento até sua obsolescência e, consequentemente, a necessidade de replanejamento. Para Souza e Zwicker (2000), o ciclo de vida representa as diversas etapas pelas quais passa um projeto de desenvolvimento e utilização de sistemas de informação. Especificamente os sistemas ERP apresentam diferenças em seu ciclo de vida em relação aos pacotes comerciais tradicionais, principalmente no que se refere a sua abrangência funcional e à integração entre seus diversos módulos. Para O'Leary (2000), embora existam muitos ciclos de vida de um sistema ERP praticados, há um consenso geral sobre as fases típicas desse ciclo de vida para implementações de ERP.

No que se refere aos modelos de ciclo de vida de sistemas de informação, a escolha de um modelo é fortemente influenciada pelo tipo de projeto. Neste contexto, cada modelo de processo, dentre os vários existentes, pode ser descrito por um fluxo de processo diferente, ou seja, há uma descrição de como as atividades metodológicas, ações e tarefas são organizadas sequencial e cronologicamente (PRESSMAN, 2011).

Segundo Pressman (2011), os modelos de processo podem ser prescritivos, sequenciais, incrementais, concorrentes e modelo pessoal e de equipe. De acordo com o autor, numa visão mais ampla, todos realizam o mesmo conjunto de atividades metodológicas genéricas: comunicação, planejamento, modelagem, construção e emprego.

Os modelos prescritivos esforçam-se para organizar e estruturar o desenvolvimento de software de acordo com o modelo genérico. No modelo de processos sequenciais, encontram-se os clássicos modelos Cascata e o Modelo $V$ com fases distintas de especificação, projeto e desenvolvimento, sugerindo um fluxo de processo linear. Já nos incrementais estão os modelos de Prototipação e Espiral, que produzem rapidamente artefatos de software incrementais, pois são iterativos por natureza e produzem rapidamente versões operacionais do software (PRESSMAN, 2011).

O modelo de processo concorrente possibilita que uma equipe de software represente elementos iterativos e concorrentes de qualquer modelo de processo, como exemplo, pode-se citar o modelo de Processo Unificado, processo de software dirigido a casos práticos, centrado na arquitetura, iterativo e incremental. Por fim, o modelo Pessoal e de equipe enfatiza a medição, o planejamento e o autodirecionamento como ingredientes chaves para um processo de software bem sucedido (PRESSMAN, 2011).

Ainda, há que se mencionarem os modelos bastante utilizados no contexto brasileiro, o proposto por Souza e Zwicker (2000), que divide o processo de implementação em três fases: processos de decisão e seleção, implementação e utilização dos sistemas ERP e da conceituação básica do ciclo de vida dos sistemas como as diversas etapas pelas quais passa um projeto de desenvolvimento e utilização de sistemas de informação (SOUZA e SACCOL, 2012), e o proposto por Audy, Andrade e Cidral (2005), utilizado neste estudo, que está estruturado em fases como pode ser visualizado na Figura 1. Salienta-se que a escolha deste modelo utilizado no presente estudo decorre do fato de ser um modelo clássico, com fases distintas e fluxo de processo linear, tendo, realmente, aplicabilidade em situações em que os requisitos são bem definidos e estáveis (PRESSMAN, 2011). 


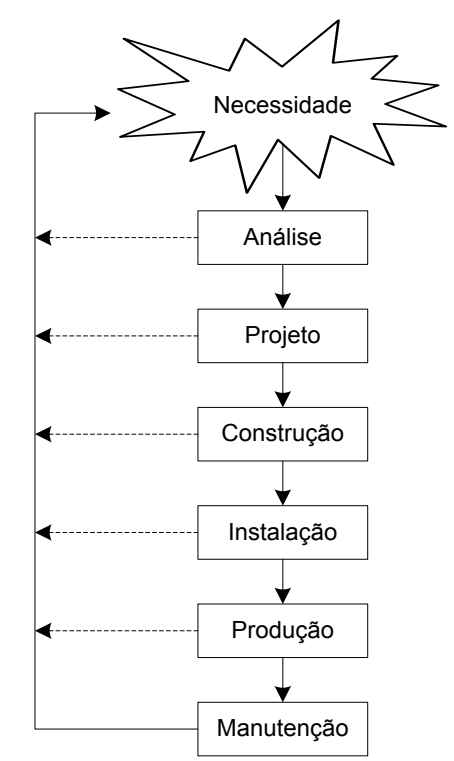

Figura 1 - Ciclo de vida dos sistemas de Informação Fonte: Adaptado pelo autor de Audy, Andrade e Cidral (2005)

A necessidade não trata propriamente de uma fase do ciclo de vida, porém é o ponto de partida para o desenvolvimento e/ou aquisição de um sistema de informação. As organizações procuram sistemas com o objetivo de solucionar problemas organizacionais. A implementação de um sistema é resumido como uma mudança na qual a organização busca melhorar seu desempenho na relação com o ambiente em que atua.

Na fase de análise, os profissionais de $\mathrm{TI}$, juntamente com usuários e gestores, definem o problema/necessidade. Após esta definição, buscam alternativas para sua resolução as quais ainda devem ser avaliados em termos de sua viabilidade técnica, viabilidade financeira e viabilidade operacional. Resultando da análise descrita, chega-se a uma alternativa a ser implementada e também as especificações técnicas a qual o sistema deverá atender.

A fase de projeto diz respeito à realização das especificações lógicas e físicas. Nesta fase, são especificados os aspectos organizacionais, humanos e tecnológicos do novo sistema. No aspecto organizacional, é o momento de realizar uma reengenharia dos processos. No aspecto humano, é o momento de especificar os requisitos comportamentais a serem cumpridos pelos recursos humanos. No aspecto tecnológico, é o momento de realizar a especificação de hardware e software os quais integrarão o novo sistema. O resultado desta fase será o detalhamento de como o novo sistema será construído e como funcionará.

$\mathrm{Na}$ fase de construção, são concretizadas as especificações que foram delineadas nas fases de análise e de projeto. No aspecto organizacional, é o momento de detalhar os novos procedimentos de trabalho. No aspecto humano, é o momento de definir e capacitar a equipe que atuará no sistema, no aspecto tecnológico e o momento de construir e testar as soluções de hardware e software. 0 resultado dessa fase é a disponibilização dos componentes organizacionais, humanos e tecnológicos.

Na fase de instalação, o novo sistema é disponibilizado e ocorre a conversão do antigo para o novo sistema. É fundamental que ocorra um planejamento da realização das atividades de conversão organizacional. Dessa forma, é necessário definir o modo como os antigos procedimentos serão migrados para os novos procedimentos. Com relação ao aspecto humano, é necessário prever os treinamentos necessários para os usuários e procedimentos para suporte de futuras dificuldades. No aspecto tecnológico, é necessária a conversão dos dados do antigo 
sistema para o novo e a disponibilização de recursos de hardware e comunicação previstos para o novo sistema. O resultado desta fase é a entrada em produção do novo sistema.

Na fase de produção, o sistema passa a fazer parte da organização. Nesta fase, os usuários ganham experiência na utilização do sistema e é onde surgirão as dúvidas quanto a operacionalização, e surgirão demandas quanto a novas funcionalidades a serem oferecidas pelo sistema, havendo, nessa fase fundamental, a disponibilização do suporte ao usuário. O processo de aplicação do sistema encerra-se formalmente nesta fase.

A manutenção é a etapa onde o sistema deve ser mantido em funcionamento, e todos os dados atualizados. Nesta fase, é necessário aperfeiçoar o sistema para atender a novas demandas do ambiente organizacional e corrigir as falhas causadas a partir do uso do sistema.

O ciclo de vida acaba no momento em que o sistema apresenta obsolescência no ponto de vista tecnológico e no ponto de vista do negócio, traduzindo-se em ineficiência e/ou ineficácia no atendimento das necessidades da organização.

\subsection{Sistemas ERP no setor público}

De acordo com Alves e Matos (2011), embora as organizações públicas não sejam o principal alvo de fornecedores de ERP, esse tipo de sistema está cada vez mais sendo implantado no setor público. E, apesar da desaceleração da economia global, tem havido uma tendência mundial de implantações de ERP neste setor (THOMAS e JAJODIA, 2004). Isto porque as organizações públicas sentiram a necessidade premente de se modernizarem, diminuindo seus custos operacionais para atender às demandas que estão ocorrendo na sociedade. Segundo Dalla Vecchia (2011), um dos importantes instrumentos de tecnologia da informação que permite diminuição de custos e aumento de eficiência é o sistema ERP.

No entender de Sommer (2011), os sistemas ERP são altamente valorizados como componente integral dos negócios modernos e iniciativas de transformação. Estas iniciativas têm suas origens no setor privado, e as lições aprendidas só foram aplicadas recentemente às organizações do setor público. Por isso, existe uma necessidade de identificar as experiências de sucesso do setor privado, métodos e modelos e aplicá-los no setor público como desafios de transformação de negócios. Neste sentido, o sucesso mundial da aplicação dos sistemas ERP no setor privado fez com que estes passassem a ser adotados como solução tecnológica também pelas grandes organizações públicas e governos de uma forma praticamente generalizada.

No entanto, a implantação de um sistema ERP no setor público é uma tarefa difícil, e não existe um grande número de pesquisas realizadas nessa área (ALVES e MATOS, 2011). As implantações de ERP estão bem estabelecidas no setor privado ao longo da última década, como resultado, os benefícios do ERP são maximizados quando uma forte ligação é estabelecida entre a abordagem de implantação e os tópicos do projeto ou medidas de desempenho em nível das empresas (AL-MASHARI, AL-MUDIMIGH e ZAIRI, 2003).

As dificuldades encontradas na implantação de sistemas ERP no setor público estão associadas principalmente, segundo Wagner e Antonucci (2004), a questões culturais e a estrutura organizacional das instituições públicas que, muitas vezes, tendem a ser complexas, consistindo em muitos departamentos e divisões, cada uma com o seu próprio gerente, regras de negócios e processos. Os autores salientam que a composição política de muitas instituições governamentais pode mudar com frequência, afetando a liderança e objetivos do projeto de implantação de ERP, criando um desafio para a manutenção e compromisso com o projeto. Além disso, a implementação do ERP em grande escala no setor público tende a ter um elevado nível de complexida- 
de organizacional, combinada com um grande número de usuários em muitos módulos do ERP. Por esta razão, são necessários cuidados adicionais, tais como questão temporal e comprometimento da equipe do projeto (WAGNER e ANTONUCCI, 2004).

Neste contexto, de acordo com Wood Jr. e Caldas (2002), a implantação de sistemas ERP geralmente envolve grandes processos de transformação organizacional, com implicações significativas no modelo de gestão da organização, estrutura, estilo de gestão e cultura e, particularmente, sobre as pessoas. Como Davenport (1998) menciona os sistemas ERP não são projetos que um dia irão acabar, mas sim um modo de vida. Eles exigem um elevado grau de alinhamento entre estratégias de negócios, estratégias de tecnologia da informação e processos organizacionais (GIBSON, HOLLAND e LIGHT, 1999). Segundo Esteves e Pastor (2001), a mudança parece ser o principal fenômeno associado a um ERP e, para lidar com a mudança de forma eficaz, é preciso estabelecer a visão de mudança no contexto técnico, social e organizacional.

Dessa forma, no contexto nacional, o governo tem lançado mão da tecnologia, uma vez que tem sofrido uma significativa pressão para modernizar-se, ou seja, está sendo impelido a promover mudanças organizacionais profundas em sua estrutura administrativa e operacionalização dos serviços que disponibiliza à sociedade (YOSHINO, 2010). Para adaptar sua atuação às exigências da sociedade, o setor público passou a estruturar seus serviços, utilizando tecnologias da informação e comunicação. Neste contexto, o uso dos sistemas ERP em organizações públicas constitui exemplo prático desta adaptação operacional das entidades governamentais às exigências da sociedade moderna.

\section{ASPECTOS METODOLÓGICOS}

Visando atender aos objetivos delineados neste estudo, realizou-se uma pesquisa de caráter qualitativo. O método escolhido para desenvolvimento da pesquisa foi o estudo de caso único. De acordo com Yin (2010), o estudo de caso caracteriza-se por ser um método de pesquisa utilizado para investigar um fenômeno contemporâneo dentro do seu contexto de vida real, especialmente quando os limites entre o fato e o fenômeno não estão claramente definidos. O método de estudo de caso foi escolhido devido ao fato de o estudo ser descritivo abrangente e relativamente complexo.

No contexto deste estudo, o sistema objeto de análise está em fase de implantação nas unidades de saúde municipais (postos de pronto atendimento, postos de saúde, farmácia popular, dentre outros). A instituição foi escolhida por se tratar de uma instituição pública, por ter um sistema de informação em fase de implantação e por este ser um caso pioneiro na região com relação à implantação de um sistema de informação específico para área de saúde na rede de pública.

A coleta de dados utilizada neste estudo foi efetuada através de dados primários e secundários. Para obtenção dos dados primários, foram realizadas entrevistas semiestruturadas, em que foram coletadas informações, abrangendo as fases do ciclo de vida de sistemas de informação que já foram realizadas e alguns aspectos pertinentes à implantação do sistema em questão. As entrevistas, realizadas no primeiro semestre de 2014, tiveram duração de aproximadamente 40 minutos cada uma. Desta forma, foram entrevistadas três pessoas, uma do setor de TI da prefeitura municipal, uma do setor de TI da secretaria de saúde do município e o analista da empresa que está implantando o software no município. Com o objetivo de garantir a confidencialidade dos dados coletados, os entrevistados foram nomeados por letras, da seguinte forma: entrevistado A, profissional de TI da prefeitura municipal; entrevistado B, profissional de $\mathrm{TI}$ da secretária de saúde do município; entrevistado C, profissional de TI da empresa responsável pela implantação do sistema no município. 
Os dados secundários foram obtidos pela análise documental, através de documentos, sites da prefeitura, da empresa fornecedora de software e folders institucionais. As entrevistas individuais foram gravadas e transcritas, com permissão dos entrevistados. Após estes procedimentos, realizou-se o tratamento e interpretação dos dados qualitativos, utilizando-se a análise de conteúdo como estratégia de análise de dados.

O estudo de implantação de sistemas de informação no município estudado é um fenômeno novo, visto que atualmente estão sendo implantados dois sistemas (um na saúde e um na educação). O município trabalha atualmente na especificação de aquisição de um novo sistema para a gestão do setor administrativo e financeiro dos processos da sede da prefeitura. Salientase que não foram encontrados registros de estudos desta natureza dentro da instituição municipal o que corrobora para a investigação e desenvolvimento deste estudo.

Considerando o fenômeno de implantação de um sistema de informação um evento complexo que demanda de um bom planejamento e um controle efetivo do cronograma pretendido, este estudo visou investigar as fases de implantação do sistema a partir do conceito de ciclo de vida dos sistemas de informação proposto por Audy, Andrade e Cidral (2005). Desta forma, foram definidas as seguintes categorias de análise, a fim de atingir ao objetivo proposto, conforme Figura 2.

\begin{tabular}{|c|l|}
\hline Categorias de análise & \multicolumn{1}{c|}{ Descrição } \\
\hline Análise & $\begin{array}{l}\text { Nesta etapa, os profissionais de TI , em conjunto com os usuários, especificam o } \\
\text { problema/necessidade e especificam a solução a ser adotada. }\end{array}$ \\
\hline Projeto & $\begin{array}{l}\text { Nesta etapa, realiza-se a especificação técnica da alternativa se solução que foi } \\
\text { escolhida na análise. }\end{array}$ \\
\hline Construção & $\begin{array}{l}\text { São concretizadas as especificações que foram definidas na análise e no deta- } \\
\text { lhamento do projeto. }\end{array}$ \\
\hline Instalação & $\begin{array}{l}\text { Nesta etapa, o sistema é disponibilizado, ocorre a conversão dos dados do anti- } \\
\text { go sistema para o novo sistema e executam-se treinamentos ao usuários. }\end{array}$ \\
\hline Produção & $\begin{array}{l}\text { Nesta etapa, o sistema passa a integrar o ambiente organizacional, gradual- } \\
\text { mente os usuários familiarizam-se com o sistema e o integram na sua rotina de } \\
\text { trabalho. }\end{array}$ \\
\hline Manutenção & $\begin{array}{l}\text { Etapa em que o sistema deve ser mantido em funcionamento, realizando as } \\
\text { devidas atualizações e aperfeiçoamento do sistema para atendimento de novas } \\
\text { demandas organizacionais. }\end{array}$ \\
\hline
\end{tabular}

Figura 2 - Categorias de análise

Fonte: Elaborado pelos autores com base no referencial teórico adotado

\subsection{Caracterização do local}

O estudo foi conduzido na rede de saúde pública em um município do interior do Rio Grande do Sul, que não possuía, até o ano de 2014, nenhuma informatização do ciclo de saúde pública. Os únicos dados informatizados eram enviados via sistema do ministério de saúde o DataSUS, software, disponibilizado pelo Ministério da Saúde que tem como objetivo a descentralização das atividades de saúde e a viabilização do controle social sobre a utilização dos recursos disponíveis, informações resumidas sem estratificação adequada para a gestão da saúde do município.

Vale acrescentar que não se trata de um pequeno município no interior do Rio Grande do Sul. Segundo dados estatísticos do Instituto Brasileiro de Geografia e Estatística (2013), o município comporta uma dimensão considerável com relação à população (273.489 habitantes) e área territorial $\left(1.788,121 \mathrm{Km}^{2}\right)$. Com relação ao aspecto da saúde, segundo estudo do Instituto Brasileiro de Geografia e Estatística (2010), os números também são significativos. A Tabela 1 apresenta essas informações. 
Tabela 1 - Assistência Médica Sanitária 2009

\begin{tabular}{c|c|l}
\hline Estabelecimentos de saúde total & 160 & Estabelecimentos \\
\hline Estabelecimentos de saúde pública total & 46 & Estabelecimentos \\
\hline Estabelecimentos de saúde pública federal & 3 & Estabelecimentos \\
\hline Estabelecimentos de saúde pública estadual & 2 & Estabelecimentos \\
\hline Estabelecimentos de saúde pública municipal & 41 & Estabelecimentos \\
\hline Estabelecimentos de saúde privado total & 114 & Estabelecimentos \\
\hline
\end{tabular}

Fonte: Instituto Brasileiro de Geografia e Estatística - Censo Demográfico (2010)

Acrescenta-se que, de acordo com os resultados da pesquisa, há quarenta e sete unidades de saúde, no município, contabilizando, além dos postos de saúde do Censo Demográfico do IBGE, também as farmácias populares, unidades odontológicas municipais e a própria secretária de saúde do município.

\subsection{Características do sistema em implementação}

O software adquirido para implementação nas unidades de saúde do município em questão é um ERP, modular, podendo ser contratado em sua totalidade e/ou apenas módulos específicos conforme necessidade do usuário. Os módulos disponibilizados pelo sistema totalizam 23 , sendo esses adquiridos pela instituição pesquisada, com exceção dos módulos de ouvidoria e vigilância sanitária, os quais não foram previstos no edital da licitação. O sistema está sendo implementando módulo a módulo, conforme cronograma elaborado pela fornecedora. O sistema, objeto deste estudo, é denominado Sistema de Informação e Gestão em Saúde e Social.

\subsection{Implantação: Análise do ciclo de vida do sistema}

O processo de implantação de um sistema de informação em uma organização é um processo de extrema complexidade que tem por objetivo a melhoria do desempenho organizacional, eficiência nos processos, melhoria na gestão dos processos, entre outros, são inúmeros os benefícios da informatização da informação. Este processo compreende um período de tempo extenso, que abrange, de forma geral, todo o ciclo de vida dos sistemas de informação, desde a percepção da necessidade, da análise e levantamento das necessidades, do projeto e especificação técnica da solução a ser comprada ou desenvolvida, construção, instalação e disponibilização da ferramenta para o usuário, a produção onde efetivamente o sistema passa a operar dentro da organização e, por fim, a manutenção do sistema para o correto funcionamento.

A implantação de um sistema de informação pode ser caracterizada como um projeto, visto que, na maioria dos casos, são definidos cronogramas de implantação, com prazo e etapas claramente definidos, compreendendo o início, meio e fim, e tem caráter temporário.

Os sistemas de informação são componentes essenciais e indispensáveis para as organizações públicas, este aspecto vem sendo percebido pelos gestores públicos municipais, como neste estudo de caso, um saldo na gestão da informação dentro de uma instituição municipal. No sistema público, o principal benefício é a agilização de processos e a possível interligação entre órgãos que implementam políticas de forma coordenada.

Pode-se afirmar que toda a organização pública que tenha como proposta a melhoria da qualidade dos seus serviços, agilidade dos processos e melhora ao atendimento oferecido ao cidadão deve primordialmente passar pelo processo de informatização. 
No âmbito do sistema público, os sistemas de informação têm como proposta auxiliar o processo decisório, o monitoramento e avaliação de políticas públicas de saúde, a mitigação de retrabalhos, melhora na comunicação interna e externa, maior confiabilidade nas informações, melhora na publicidade das informações.

Visando alcançar o objetivo proposto de investigar o processo de implantação de um sistema de informação em uma instituição pública de saúde, foram analisadas as seguintes etapas de implantação: análise, projeto, construção, instalação, produção e manutenção.

Com relação à fase de análise, que trata da etapa onde o profissional de sistemas de informação em conjunto com os usuários e gestores, definem o problema. A necessidade de implantação do sistema, no caso estudado, foi decorrente de não existir anteriormente um sistema de informação baseado em computador, como pode ser observado através das seguintes falas:

Surgiu em virtude de não ter nenhum sistema informatizado, todo o processo ser em papel, sem controle efetivo, processo arcaico (ENTREVISTADO A).

Anteriormente, o processo não era informatizado, todo processo era em papel, custo alto, os pacientes realizavam três consultas em três postos de saúde. Hoje, com o sistema (on-line), sabe-se que o paciente já consultou, já realizou determinado exame, não sendo necessário realização em duplicidade, melhoria de gestão com os registros armazenados e possibilidade de planejamento futuro (ENTREVISTADO A).

A necessidade surgiu devido à falta de controle da gestão de saúde, não se tinha controle, não se tinha indicadores, não se sabia o que estava sendo feito, o que não estava sendo feito, as verbas que vinham não se controlavam, era um descontrole, precisava-se de um sistema informatizado de gestão, que trouxesse estes dados e pudesse melhorar a saúde no município (ENTREVISTADO B).

Ainda na etapa de análise, são elencados os problemas organizacionais que motivam a busca por uma solução informatizada para a gestão da informação. Dentre os problemas citados, foi observado que o poder público municipal começa a reconhecer o valor da informação. Conforme Stair e Reynolds (2011), o valor da informação está ligado à forma na qual ela auxilia os tomadores de decisão a atingir seus objetivos. Em sua obra, Rezende e Abreu (2008) descrevem que a informação, atualmente, tem um valor altamente significativo e pode representar um grande poder para quem possui, seja pessoa ou instituição. Tais aspectos podem ser identificados nas seguintes falas:

Sem informatização existem muitos problemas de gerência, que não consegue determinar muitas coisas para realização de planejamento (ENTREVISTADO A).

Para saber a quantidade de medicamentos que determinado posto consumiu era necessário buscar em papel, tornando-se moroso o levantamento dos dados (ENTREVISTADO A).

Gerencia todos os programas de saúde tanto no âmbito nacional, estadual e municipal (ENTREVISTADO B).

Com relação à fase de projeto, é muito importante que a equipe de planejamento realize uma investigação sobre os sistemas com os quais se pretende trabalhar. Devem-se realizar visitas em locais já informatizados, realizar pesquisas de campo com o objetivo de visualizar as alternativas existentes no mercado. No caso estudado, o poder público municipal contatou diversos fornecedores, com o objetivo de conhecer seus sistemas e realizar um melhor detalhamento dos requisitos necessários a serem atendidos, isso foi identificado com base na seguinte fala: 
Em 2009, começou o projeto, foram chamadas empresas para demonstrar o que tinham, com base naquelas demonstrações dos projetos das diversas empresas que quiseram demonstrar o seu produto, foi feito um objeto... (ENTREVISTADO B).

$\mathrm{Na}$ fase de projeto, são nominados representantes dos diversos setores envolvidos da organização para acompanhamento de todo o projeto de especificação, aquisição e implementação da solução. Em sua obra, Rezende e Abreu (2008) afirmam que a elaboração de um projeto de TI deve ser sempre realizada por uma equipe multidisciplinar ou multifuncional, adequada para cada projeto e para cada empresa. No decorrer do estudo, observou-se que foi constituída uma equipe colaborativa para acompanhamento do projeto, o que pode ser identificado nas seguintes falas:

... parte técnica da TI da prefeitura, juntamente com funcionários da secretária de saúde, foi formado um grupo multidisciplinar para construção do termo de inferência (ENTREVISTADO A).

A secretaria de saúde e a secretária de gestão e modernização administrativa através da superintendência tecnologia de informação integraram a equipe de projeto... (ENTREVISTADO B).

No entanto, pode-se observar que, em alguns momentos, não foi prestado o suporte efetivo pelas áreas envolvidas, conforme mostra a seguinte fala:

\begin{abstract}
Basicamente quem fez foi o ... (era superintendente de TI), não foi só o ..., cada vez que ele montava o objeto, ele encaminhava aos setores responsáveis, porém nem sempre o retorno acontecia. Foi construído o objeto com base nas informações que eram repassadas para ele. O termo de referência foi construído de forma satisfatória, porém com o tempo observou-se que algumas coisas ficaram fora, por exemplo, a parte de ouvidoria ficou de fora do edital, porém a fornecedora dispõe deste módulo, então resta saber se o município vai querer adquirir este recurso, se a empresa vai fornecer, quanto vai custar, a parte de vigilância sanitária também ficou fora.... (ENTREVISTADO B).
\end{abstract}

A fase de construção é o momento em que são concretizadas todas as especificações que foram definidas na fase do projeto; no caso do estudo, esta fase foi caracterizada principalmente pelo lançamento do edital de licitação pública para aquisição do software. Conforme Art $2^{\circ}$ da Lei $n^{\circ}$ 8.666, todas as obras, serviços, compras, alienações, concessões, permissões e locações da Administração Pública, quando contratadas de terceiros, serão necessariamente precedidas de licitação, ressalvadas as hipóteses previstas em lei. Esta fase é caracterizada nas seguintes falas:

Por licitação, foram definidos os requisitos do sistema, 2 ou 3 empresas apresentaram as propostas, ganhou a de menor valor (ENTREVISTADO A).

Por licitação ... não foi técnica e preço, foi só preço, dentro do objeto que foi construído (ENTREVISTADO B).

Eles conseguiram licitar o software em 2010 ou 2011 (ENTREVISTADO C).

Na realização das entrevistas, foi identificado que existiram problemas desde o edital de licitação até o momento do início de implantação do sistema estudado, sendo identificado a seguir:

Em 2009, começou o projeto, foram chamadas empresas para demonstrar o que tinham, com base naquelas demonstrações dos projetos das diversas empresas que quiseram demonstrar o seu produto, foi feito um objeto, este objeto foi licitado, na licitação ocorreram problemas... isso ficou parado por dois anos mais ou menos, quando liberou 
que foi em 2013, acho que em junho ou julho, aí então que começou a implementação, que daí a empresa veio, assinou o contrato ... começou o serviço efetivamente em novembro de 2013 (ENTREVISTADO B).

O sistema de ... é separado do sistema da saúde, é outra empresa, mas a licitação tinha dois objetos, um objeto era o sistema de gestão da saúde e o outro objeto era o sistema de gestão da ... então eles resolver fazer isto andar junto, só que se tivessem sido duas licitações, cada uma com o seu objeto, talvez o da saúde já tivesse sido implantado, mas como foi uma licitação com dois objetos, parou um parou o outro (ENTREVISTADO B).

Uma característica da fase de construção é a realização do treinamento dos usuários para a operação do sistema, este estudo buscou identificar como ocorreu e está acontecendo o processo de treinamento aos usuários, o que pode ser visualizado nas falas que seguem:

É realizado por representante da empresa que está fornecendo o software, é realizada em cada unidade que o sistema está sendo implantado (ENTREVISTADO A).

Uma equipe da empresa fornecedora é dimensionada de acordo com a demanda de treinamentos na região, quando se observa uma demanda elevada, é solicitado a sede da empresa a disponibilização de pessoal para ministrar os treinamentos (ENTREVISTADO C).

Dois tipos, a campo na implementação do sistema e treinamentos coletivos como, por exemplo, estou solicitando a convocação de todo o pessoal que trabalha com vacinas, pois será feito um treinamento coletivo inicial para dar como concluída esta etapa, e assim que os computadores estiverem disponíveis nas unidades, novamente a campo a gente dá um reforço ao treinamento..., ao término do treinamento é assinada uma ficha para comprovação do treinamento realizado, inclusive a ficha dispõe de um campo de reclamações. Se um usuário não quer utilizar o sistema, isso é declarado no ato, com assinatura do declarante e a fornecedora repassa tal informação à administração pública (ENTREVISTADO C).

Na fase de instalação, é o momento em que o novo sistema é disponibilizado e ocorre a conversão dos dados do sistema antigo para o novo sistema. Quanto à disponibilização do sistema, pode-se identificar que este ainda não está operando de forma consolidada nas instituições, conforme as falas abaixo:

Eu tenho em torno de 30 unidades já com o sistema rodando, ao total são 47 unidades .. nós termos em torno de 30 unidades já com o sistema instalado e rodando em operação, não todos os módulos mas já operando (ENTREVISTADO C).

Plenamente nenhuma, acreditamos que em dois meses sistema já estará operando, contado com a infraestrutura pronta e o hardware disponível (ENTREVISTADO B).

No transcorrer do estudo, foram identificados os principais fatores que estão influenciando no atraso da implementação do sistema. Segundo Audy, Andrade e Cidral (2005), o principal foco dos problemas na implementação de sistemas diz respeito às dimensões organizacional e humana, neste sentido observa-se que a adequação tecnológica é um requisito mínimo, porém não suficiente para o sucesso da implementação de um sistema de informação. A seguir são apresentadas as falas onde foram identificados os problemas que influenciam a implementação do sistema em questão:

Eu não tenho a estrutura completa para execução de $100 \%$ do sistema (ENTREVISTADO C). A gente está aguardando a chegada dos computadores que estão sendo locados (ENTREVISTADO B). 
... o problema é estrutural, é de falta, teve uma falha no processo, esta parte deveria ser antes da implementação ... (ENTREVISTADO C).

A licitação do software, do hardware e da infraestrutura deveria ter sido feita junto, só que a do software que correu, a do hardware e de rede parou em algum lugar ... o que que aconteceu, mesmo com a parada de dois anos judicial (software) esta outra não foi para frente ... é o principal motivo da não entrada em operação do sistema, se tivéssemos infraestrutura de rede e máquinas (hardware) o sistema já estava praticamente pronto (ENTREVISTADO B).

Alguns setores têm carência de recursos humanos, é a principal reclamação que eu escuto, eu não tenho como analisar se isto é real, mas realmente há alguns lugares que tem apenas uma pessoa que faz tudo... (ENTREVISTADO C).

Na fase de instalação, também é realizada uma etapa importante de importação de dados, como o processo era na sua grande parte realizado em papel, não foram carregados dados históricos, porém ocorreu uma alimentação inicial de dados com o objetivo de reduzir algumas atividades dos servidores municipais, conforme segue:

Como o sistema que se usava em alguns lugares, não era um sistema oficial, não houve migração dos dados, os únicos dados que foram migrados, foram os dados do cartão SUS (cadastro de pacientes) (ENTREVISTADO B).

Dados do cartão SUS e do CNES (cadastro das unidades de saúde, e profissionais que trabalham no município), têm todas as informações e vínculo dos profissionais que trabalham no município, especialidade, carga horária e equipes de PSF (ENTREVISTADO C).

Estes dados do sistema do SUS foram importados para dar um start inicial, nome endereço, telefone, é o cadastro do usuário (paciente) (ENTREVISTADO C).

A fase de produção é o momento em que o sistema passa a fazer parte da estrutura da organização, os usuários passam gradualmente a usar o sistema, neste momento, é disponibilizado o suporte ao usuário. Conforme Audy, Andrade e Cidral (2005), é nesta etapa que o processo de implantação do sistema se encerra formalmente, quando o sistema entra em produção. Na investigação realizada, pode-se observar que a instituição estudada ainda não encerrou a fase de instalação. Em algumas unidades do sistema de saúde municipal, o sistema está operando de forma parcial, desta forma, pode-se inferir que o processo de implantação do sistema de informação ainda não está concluído. Assim, as fases de produção e manutenção não puderam ser efetivamente avaliadas neste estudo, podendo estas ser analisadas em pesquisas futuras.

Segundo Oliveira (2008), é difícil avaliar, de forma quantitativa, os benefícios da utilização de um sistema de informação, entretanto podem-se citar algumas hipóteses quanto ao impacto de um sistema de informação. Dentre as hipóteses citadas na literatura, as observadas na instituição estudada, podemos citar redução de custos das operações, melhoria no acesso às informações, melhoria nos serviços realizados e oferecidos, redução do grau de centralização das decisões, melhor interação com os fornecedores, redução de funcionários em atividades burocráticas, entre outras.

No decorrer do estudo, foram identificados ganhos substanciais, tanto para o poder público, quanto para a população atendida no município, estes são inerentes ao processo de informatização. A seguir são apresentadas algumas falas que caracterizam alguns ganhos observados no estudo: 


\begin{abstract}
As consultas especializadas que eram centralizadas aqui (sede da secretária de saúde), toda a quarta-feira saía da rota, um veículo que passa em todas as unidades pegando os papéis das consultas especializadas para vir tudo para cá e o pessoal digitar aqui, isso não existe, as unidades agendam de lá, o paciente chega lá e sai com a consulta agendada a partir da unidade ... (ENTREVISTADO C).
\end{abstract}

Às vezes, as pessoas tinham que ir lá à unidade, depois vir aqui, depois tinha que ir à especializada, depois tinha que ir à unidade, era muito mais demorado, hoje ela faz tudo lá na unidade direto (ENTREVISTADO B).

Toda a documentação que vinha para um setor fazer deixou de existir, todo o combustível que se usava para passar nas quartas-feiras em todas as unidades de saúde deixou de ser utilizado, o carro deixou de ser utilizado, para o usuário é melhor porque o usuário chega lá, ele já sai com o dia da consulta especializada dele marcada... dia tal, tal hora, você comparece em tal lugar, antes não, a pessoa ia no posto, voltava dali uns 10 ou 15 dias para ver se já estava marcado, para, quando estava marcado, aí ela ia no posto não tava ainda, ai ela ligava para o posto não estava ainda ou ligavam daqui para ele para chamar, agora não, ela já sai lá do posto com a consulta marcada (ENTREVISTADO B).

\begin{abstract}
Existe um módulo do sistema, um portal, que eu não sei se está no edital, mas a empresa dispõe, a pessoa (paciente) se cadastra no portal e ganha um usuário e senha, ela pode entrar no site da prefeitura no qual vai ser direcionada para o portal, que ela tem acesso à carteira de vacina dela, que lugar ela está na fila de espera, ela pode visualizar os medicamentos que existem na rede básica de farmácias para saber se tem o medicamento que ela toma ... (ENTREVISTADO C).
\end{abstract}

Em relação aos ganhos, são notórios os avanços que a administração pública passará a usufruir após a conclusão do processo de implantação do sistema de informação, objeto deste estudo. Espera-se também um aumento da satisfação dos usuários internos, servidores municipais, e dos usuários externos, pacientes da rede pública municipal de saúde.

\title{
5 CONSIDERAÇÕES FINAIS
}

A informatização de instituições públicas e privadas vem se tornando tendência e tem como objetivo a melhoria na gestão dos recursos e a melhoria na prestação dos serviços. Nesse contexto, observando a importância da informatização de órgãos públicos, este estudo teve como objetivo investigar a implantação de um sistema de informação em um órgão público municipal. A ideia de informatização partiu da administração municipal, com o objetivo de melhorar a gestão do sistema de saúde no município e a partir da necessidade de melhoria na prestação de serviços ao cidadão.

Nas entrevistas realizadas, foi possível identificar a passagem do processo de implantação do sistema pelas fases do ciclo de vida dos sistemas de informação que já foram concluídas na organização, objeto de análise desta pesquisa. Cada uma das fases foi caracterizada de forma clara, cada uma com suas características particulares. Foi possível identificar que o processo de implantação encontra-se na fase de instalação, pois o sistema opera em alguns setores, porém não opera com sua capacidade total.

Com relação à fase de análise, que trata da etapa onde o profissional de sistemas de informação, em conjunto com os usuários e gestores, definem o problema, a necessidade de implantação do sistema, no caso estudado foi decorrente de não existir anteriormente um sistema de informação baseado em computador. A fase de projeto diz respeito à realização das especificações lógicas e físicas. No caso estudado, o poder público municipal contatou diversos fornecedores, com o objetivo de conhecer seus sistemas e realizar um melhor detalhamento dos requisitos necessários a serem atendidos. 
A fase de construção, momento em que são concretizadas todas as especificações que foram definidas na fase do projeto, no caso estudo, esta fase foi caracterizada principalmente pelo lançamento do edital de licitação pública para aquisição do software. Ainda nesta fase, sobre a realização do treinamento dos usuários para a operação do sistema, foi possível observar que o treinamento é realizado por representante da empresa fornecedora do software, em cada unidade que o sistema está sendo implantado.

Na fase de instalação, momento em que o novo sistema é disponibilizado e ocorre a conversão dos dados do sistema antigo para o novo sistema, foi possível perceber que até a data da pesquisa não havia sido concluída a instalação do software em todas as unidades previstas. Também foram observados problemas de estrutura de hardware com capacidade adequada ao sistema e de importação de dados, uma vez que alguns dados não foram importados ao sistema novo.

Diante deste contexto, foi possível observar que a aquisição de um sistema de informação pela administração municipal foi um grande avanço na administração da saúde do município. A partir deste momento, o município passou a dispor de todos os dados referentes a atendimentos realizados, produtos consumidos e estatísticas de prazo. Com estes dados, o município passou a gerar informações de valor para o planejamento das políticas públicas de saúde, planejamento de recursos humanos e planejamento de materiais, refletindo todas estas ações para a população do município atendido.

Foi possível identificar que o sistema adquirido pela administração municipal é um sistema consolidado no mercado, com recursos avançados para gestão e planejamento, podendo-se assegurar que o município entra em uma nova era na administração da saúde.

No desenvolvimento do trabalho, identificaram-se os principais problemas enfrentados no desenvolvimento do projeto de implantação do sistema que é o atraso na aquisição de har$d$ ware e o atraso na infraestrutura (link de internet e parte elétrica), sendo que este processo foi tramitado em paralelo à aquisição do sistema de informação, porém, mesmo com a paralisação de aproximadamente dois anos no processo de aquisição do sistema, os computadores e a infraestrutura não foram preparados para a implantação do mesmo. No decorrer das entrevistas, emergiu uma possível solução para casos futuros, o sistema, o hardware e toda a infraestrutura, serem objetos de um mesmo processo licitatório, tendo apenas um fornecedor, garantindo, assim, maior rapidez no processo de implantação de sistemas de informação, evitando a incompatibilidade de equipamentos e sistemas.

Este estudo alcançou o objetivo e justificou sua importância, uma vez que não foram identificados estudos similares junto à administração municipal, e esse passa a servir como material de apoio para projetos futuros de implantação de sistemas de informação pelo poder público municipal. No entanto, foram identificadas algumas limitações, como por exemplo, o número reduzido de entrevistas e o fato de que duas fases do ciclo de vida dos sistemas até a presente pesquisa não terem sido implementadas.

Sugere-se que este trabalho seja complementado com uma nova pesquisa, a fim de analisar as demais fases do ciclo de vida do sistema que, até a data do estudo, ainda não haviam sido concluídas, ou seja, as fases de produção e manutenção, bem como do impacto da implantação de um sistema de informação no poder público municipal. Tal estudo poderia ser conduzido a partir da percepção do usuário, na forma de uma pesquisa quantitativa e utilizando questionário específico para este fim. 


\section{REFERÊNCIAS}

ABUGABAH, A.; SANZOGNI, L. Information Systems and Performance: An analytical approach to understand IS value in business organizations. In C. Ardil (Ed.), 2009.

AL-MASHARI, M.; AL-MUDIMIGH, A.; ZAIRI, $M$. Enterprise resource planning: A taxonomy of critical factors. European Journal of Operational Research, v. 146, p. 352-364, 2003.

ALVES, M. C. G.; MATOS, S. I. A. An Investigation into the Use of ERP Systems in the Public Sector. Journal of Enterprise Resource Planning Studies, v. 2011, 2011.

Art $2^{\circ}$ da Lei $\mathrm{N}^{\circ} 8.666$, d. 2. (s.d.). Planalto.gov. br. Acesso em 17 de Junho de 2014, diponível em LEI N 8.666, de 21 de Junho de 1993: http://www.planalto.gov.br/ccivil_03/leis/ I8666cons.htm

AUDY, J. L., ANDRADE, G. K.; CIDRAL, A. Fundamentos de Sistemas de Informação. Porto Alegre: Bookman, 2005.

DALLA VECCHIA, A. F. Sistemas ERP: A Gestão do Processo de Implantação em Universidade Pública. Dissertação. - Universidade Federal de Santa Maria (Mestrado em Engenharia de Produção) / Aldiocir Francisco Dalla Vecchia. - 2011. 178p.

DAVENPORT, T. H. Putting the Enterprise into the Enterprise System. Harvard Business Review, p. 121-131, Jul./Aug., 1998.

ESTEVES, J.; PASTOR, J. Enterprise Resource Planning Systems Research: An Annotated Bibliography. Communications of Association for Information Systems, v. 7 n. 8, 2001.

Fundação Getulio Vargas - Escola de Administração de São Paulo. (2014). Acesso em 20 de 05 de 2014, disponível em http:// eaesp.fgvsp.br/sites/eaesp.fgvsp.br/files/ pesqti-gvcia2014noticias.pdf
GIBSON, N.; HOLLAND, C.; LIGHT, B. Enterprise Resource $P$ lanning: A Business Approach to Systems Development. In: $32^{\text {nd }}$ Hawaii International Conference on Science Systems HICSS, Maui, Hawaii, 1999.

IDC Brasil. Acesso em 01 de fevereiro de 2016, disponível em http://www.idcbrasil.com.br/ releases/news.aspx?id=1970

Instituto Brasileiro de Geografia e Estatística(IBGE). Acesso em 08 de Junho de 2014, disponível em Censo Demográfico 2010: http://cidades.ibge.gov.br/xtras/perfil. php?lang $=\&$ codmun $=431690$

Instituto Brasileiro de Geografia e Estatística(IBGE). Acesso em 08 de Junho de 2014, disponível em http://cidades.ibge.gov. $\mathrm{br} / \mathrm{xtras} /$ perfil.php?lang $=\&$ codmun $=431690$

KIVINEN, T.; LAMMINTAKANEN, J. The success of a management information system in health care: A case study from Finland. International Journal of Medical Informatics, n. 82, p. 9097, 2013.

LAUDON, K. C.; LAUDON, J. P. Sistemas de informação gerenciais. Tradução Thelma Guimarães, reviasão Belmito N. João. - 7. ed. São Paulo: Pearson Prentice Hall, 2007.

LAUDON, K. C.; LAUDON, J. P. Sistemas de informação gerenciais. Tradução Luciana do Amaral Teixeira, revisão técnica Belmito $\mathrm{N}$. João. - 9 ed. - São Paulo: Pearson Prentice Hall, 2010.

O'LEARY D. E. Enterprise resource planning systems. Cambridge, UK: Cambridge Univ. Press, 2000.

O'LEARY, D. E. Knowledge management across the enterprise resource planning systems life cycle. International Journal of Accounting Information Systems, v. 3, p. $99-110,2002$.

OLIVEIRA, D. P. R. Sistemas de informações gerenciais: estratégicas, táticas, operacionais 12 ed. - . São Paulo: Atlas, 2008. 
PRESSMAN, R. S., Engenharia de Software: uma abordagem profissional, 7ạ Edição, McGraw-Hill-Bookman, Porto Alegre, 2011.

REZENDE, D. A.; ABREU, A. F. Tecnologia da Informação Aplicada a Sistemas de Informação Empresariais: o papel estratégico da informação e dos sistemas de informação nas empresas. - 5 ed. - São Paulo: Atlas, 2008.

SANJA, M. M. Impact of Enterprise Resource Planning System in Health Care. International Journal of Academic Research in Business and Social Sciences, v. 3, n. 12, 2013.

SANT'ANNA, P.R.; LONGO, O. C.; BARONE, F. M.; COVA, C. J.; OLIVEIRA, F. A. Tecnologia da informação como ferramenta para a análise econômica e financeira em apoio à tomada de decisão para as micro e pequenas empresas. Revista de Administração Pública, n.45, v.5, 2011.

SANTOS, A. de A. ERP e Sistemas de Informações Gerenciais. São Paulo: Atlas, 2013.

SHANKARNARAYANAN, S. ERP Systems: using IT to gain a competitive advantage, 2014. Retreived from < http://www.angelfire.com/ co/troyc/advant.html>.

SOMMER, R. Public Sector ERP Implementation: Successfully Engaging Middle-Management. Communications of the IBIMA, v. 2011, 2011.

SOUZA, C. A.; SACCOL, A.Z. Organizadores. Sistemas ERP no Brasil: teoria e casos. - 1.ed. - 7.reimpr. - São Paulo: Atlas, 2012.

SOUZA, C. A.; ZWICKER, R. Ciclo de vida de sistemas ERP. Caderno de pesquisas em administração, São Paulo. v. 1, n. 11, 1은 trim.,2000.

STAIR, R. M.; REYNOLDS, G. W. Princípios de Sistemas de Informação: uma abordagem gerencial. Tradução Flávio Soares Corrêa da Silva, Giuliano Mega, Igor Ribeiro Sucupira. São Paulo: Cengage Learning, 2011.
THOMAS, G.; JAJODIA, S. Commercial off-theShelf Enterprise Resources Planning Software Implementations in the Public Sector: Practical Approaches for Improving Project Success. The Journal of Government Financial Management, v. 53, n. 2, p.12-18, 2004.

TURBAN, E.; RAINER, R. K.; POTTER, R. E. Administração de tecnologia da informação: teoria e prática. Tradução Daniel Vieira. - 3 ed. - Rio de Janeiro: Elsevier, 2005.

WAGNER, W.; ANTONUCCI, Y. L. An Analysis of the Imagine PA Public Sector ERP Project. In: Proceedings of the $37^{\text {th }}$ Hawaii International Conference on System Sciences, 2004.

WATSON R. T. Information Systems, The global text project, Zurich, Switzerland. Acesso em 01 de Fevereiro de 2016, disponível em http://globaltext.terry.uga.edu/userfiles/pdf/ Information\%20Systems.pdf

WOOD JR, T.; CALDAS, M. P. A Hora do Pesadelo: Adoção e Implementação de Sistemas Empresariais. Revista de Estudos Organizacionais, Maringá, v. 2, p. 23-36, 2002.

YIN, R. K. Estudo de caso: planejamento e métodos. Tradução Ana Thorell; revisão Técnica Cláudio Damacena. - 4. ed.- Porto Alegre: Bookman, 2010.

YOSHINO, C. K. N. Fatores críticos de sucesso como antecedentes da aceitação de um sistema de informação em uma universidade federal. Dissertação - Universidade Federal do Rio Grande do Norte (Mestrado em Administração) / Cristina Kazumi Nakata Yoshino, 2010. 